\title{
Oral Mucosa Tissue Equivalents for the Treatment of Limbal Stem Cell Deficiency
}

Anna R. O'Callaghan*, Marc A. Dziasko, Radhika Sheth-Shah, Mark P. Lewis, and Julie T. Daniels

Dr. A. R. O’Callaghan, Dr. M. A. Dziasko, R. Sheth-Shah, Prof. J. T. Daniels

Cells for Sight, UCL Institute of Ophthalmology, University College London, London EC1V 9EL, UK

Email of corresponding author: anna.ocallaghan@alumni.ucl.ac.uk

Prof. M. P. Lewis

National Centre for Sport and Exercise Medicine (NCSEM), School of Sport, Exercise and Health Sciences, Loughborough University, Leicestershire, LE11 3TU, UK

Keywords: oral mucosa, limbal stem cell deficiency, tissue equivalents, oral mucosal fibroblasts

\begin{abstract}
:
Cultured limbal and oral epithelial cells have been successfully used to treat patients with limbal stem cell deficiency (LSCD). The most common culture method for these cell therapies utilises amniotic membrane as a cell support and/ or murine 3T3s as feeder fibroblasts. The aim of this study was to refine the production of autologous oral mucosal cell therapy for the treatment of LSCD. Real Architecture for 3D Tissue (RAFT) was used as an alternative cell culture support. In addition, oral mucosal cells (epithelial and fibroblast) were used as autologous alternatives to donor human limbal epithelial cells (HLE) and murine 3T3s. The following tissue equivalents were produced and characterised: firstly, for patients with bilateral LSCD, an oral mucosal tissue
\end{abstract}


equivalent consisting of human oral mucosal epithelial cells on RAFT supported by human oral mucosal fibroblasts (HOMF). Secondly, for patients with unilateral LSCD, HLE on RAFT supported by HOMF. For both tissue equivalent types, features of the cornea were observed including a multi-layered epithelium with small cells with a stem cell like phenotype in the basal layer and squamous cells in the top layers, and p63 $\alpha$ and PAX6 expression. These tissue equivalents may therefore be useful in the treatment of LSCD.

\section{Introduction:}

Transparency of the cornea, on the front surface of the eye, is essential for vision. The outermost corneal epithelium is maintained by a population of limbal epithelial stem cells (LESC) which reside in limbal crypts at the periphery of the cornea. Depending on the cause, loss or damage to the LESC population can result in blinding limbal stem cell deficiency (LSCD) of one or both eyes. ${ }^{[1]}$ The technique of transplanting autologous (patient's own) LESC cultured from a small limbal biopsy of the healthy contralateral eye has a success rate, in terms of visual acuity and ocular surface stability, of greater than $70 \%$ in this patient group. ${ }^{[2]}$ However, a significant therapeutic challenge remains for patients with bilateral injury or disease where no healthy limbus is available for harvesting LESC. Cultured allogeneic (donor) LESC therapy has been used with variable success. ${ }^{[1,3-9]}$ A major drawback is the requirement for systemic immunosuppression to prevent rejection. Hence, the COMET protocol for transplanting autologous epithelial cells cultured from inside the mouth was developed. COMET 'Cultivated oral mucosal epithelial transplantation' has a success rate, in patients with severe ocular surface disorders, of approximately $50 \%$ at 3 years. ${ }^{[10,11]}$ Therefore an unmet clinical need remains for bilateral cases of LSCD, and to improve the success rate of COMET. 
For COMET, human oral mucosal epithelial cells (HOME) are most commonly cultured on amniotic membrane with murine $3 \mathrm{~T} 3 \mathrm{~s}$ as a feeder fibroblast, and the use of bovine serum (culture methods reviewed by Utheim et al. 2016). ${ }^{[12]}$ For cell therapy application the ideal would be to produce an autologous cell product using a fully defined culture system free of animal-derived products in order to meet regulatory ideals, comply with good manufacturing practice (GMP), and eliminate the need for immunosuppression. Any new culture method would however need to be as efficacious as possible with equivalent results to the current (gold standard) methods.

We have developed type I collagen-based 'RAFT' (Real Architecture For 3D Tissue) tissue equivalents, ${ }^{[13]}$ for the purpose of manufacturing biomimetic limbal and corneal tissues populated with multiple cell types. ${ }^{[14-16]}$ In addition to being a reproducible substrate RAFT also allows cells to be incorporated into the $3 \mathrm{D}$ collagen matrix.

We have previously shown that LESC physically interact with melanocytes and a stromal cell population in the limbal crypts. ${ }^{[17]}$ Also, cultured human limbal fibroblasts (HLF) are able to maintain LESC in vitro in the absence of serum via the paracrine secretion of soluble mediators including IL-6. ${ }^{[18]}$ Damage to the limbal crypt architecture can occur in $\operatorname{LSCD},{ }^{[19]}$ suggesting potential for ablation of stromal cells and their supporting role for LESC in the niche. Hence, it might be beneficial to restore communication between cultured epithelial and stromal cells for improved epithelial culture success. Indeed, our previous work has suggested that HLE-HLF tissue equivalents may be advantageous over HLE only tissue equivalents in terms of improved epithelial organisation and basement membrane protein deposition. ${ }^{[15]}$ We have also shown in a $2 \mathrm{D}$ co-culture system that human oral mucosal fibroblasts (HOMF) are a suitable feeder fibroblast for the expansion of epithelial cells (both limbal and oral). ${ }^{[20]}$ 
The aim of this study was to investigate the use of the following in combination as a potentially safer and more defined culture system to the current gold standard method for the production of epithelial cells for use in the clinic to treat LSCD: 1. RAFT as an alternative cell culture substrate to biologically variable amnion. 2 . The use of HOMF as an autologous alternative to murine $3 \mathrm{~T} 3 \mathrm{~s} .3$. The use of HOME as an autologous alternative to donor HLE for cases of bilateral LSCD. Tissue equivalents with the potential to be autologous were produced and characterised. Firstly, for bilateral LSCD, HOME on RAFT supported by HOMF (oral mucosal tissue equivalent). Secondly, for unilateral LSCD, HLE on RAFT supported by HOMF (cornea-oral hybrid tissue equivalent). Controls with HLF and 3T3 were included to compare how effective HOMF would be as feeder fibroblasts in the tissue equivalents. See Figure 1 for a comparison of the culture system used in this study and the typical method for producing HOME for the treatment of LSCD. Epithelial cells (HOME and HLE) were successfully cultured using the method described. This culture system may therefore be useful for the culture of epithelial cells for the treatment of LSCD.

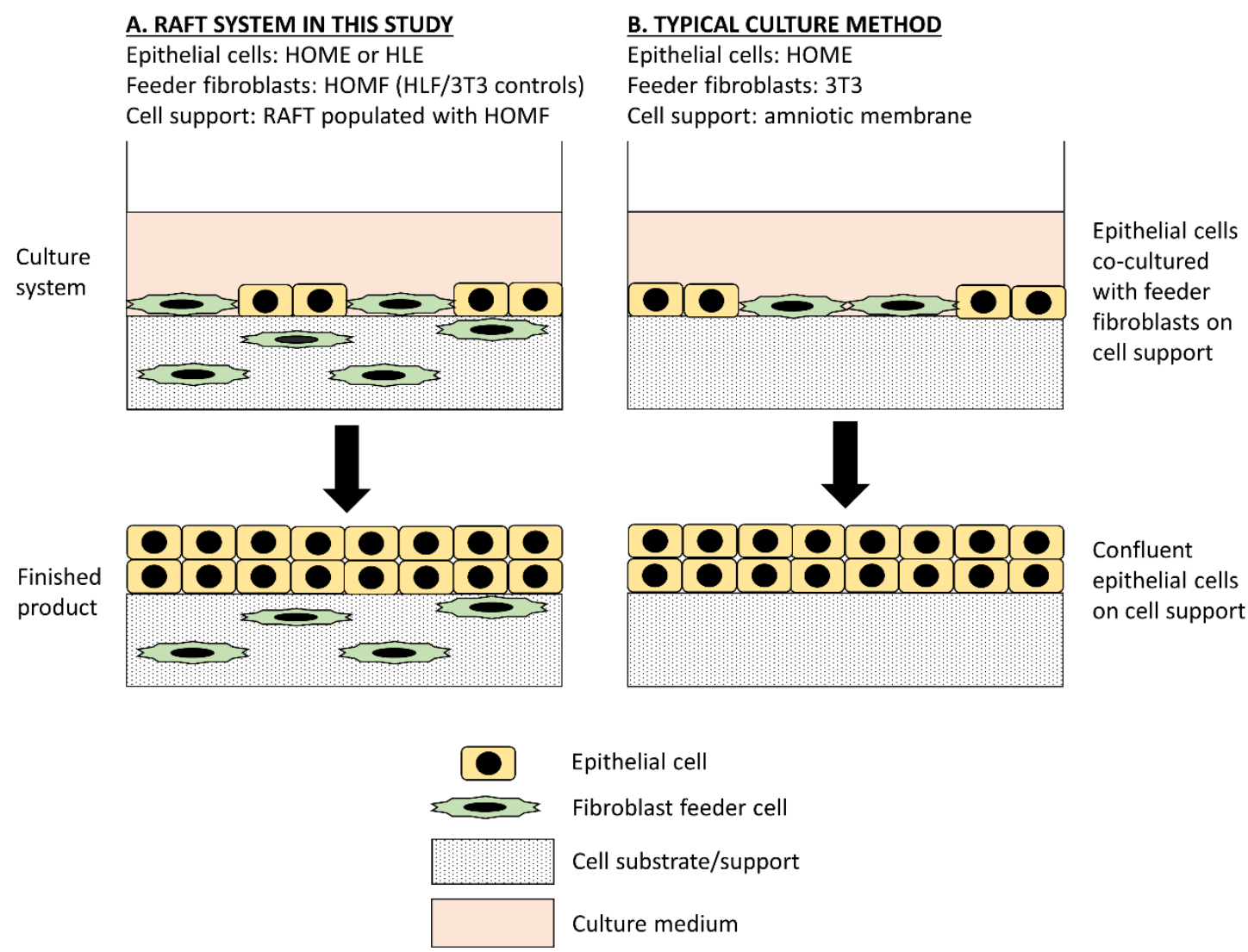


Figure 1. Comparison of the culture system used in this study (A) with the typical culture method used for culturing HOME for the treatment of LSCD (B). In both A. and B. HOME are co-cultured with feeder fibroblasts on a cell support to produce a confluent layer/layers of epithelial cells. A. HOMF were used as feeder fibroblasts in order to eliminate murine $3 \mathrm{~T} 3 \mathrm{~s}$ from the culture system. In addition, the RAFT cell support was populated with fibroblasts mimicking the fibroblast populated stroma found in the cornea. Controls with HOMF replaced by the following fibroblasts: 3T3s and HLF were also studied, as was the use of HLE instead of HOME. For B. amniotic membrane is most commonly used as a cell support.

HOME: human oral mucosal epithelial cells; LSCD: limbal stem cell deficiency; HOMF: human oral mucosal fibroblasts; RAFT: Real Architecture For 3D Tissue, HLF: human limbal fibroblasts; HLE: human limbal epithelial cells.

\section{Results}

\subsection{Multi-layered epithelium observed in oral mucosal and cornea-oral hybrid tissue} equivalents

A confluent multi-layered epithelium similar to that found in the human cornea was observed for all epithelial-fibroblast tissue equivalent combinations (Figure 2, B and C). The thickness of the epithelium varied along the tissue equivalent sections (data not shown). The Bowman's layer is an acellular layer separating the corneal epithelium and the corneal stroma, and is not present at the limbus (Figure 2B). The tissue equivalents do not have such a layer, and in this respect are more structurally similar to the limbus than the cornea. 

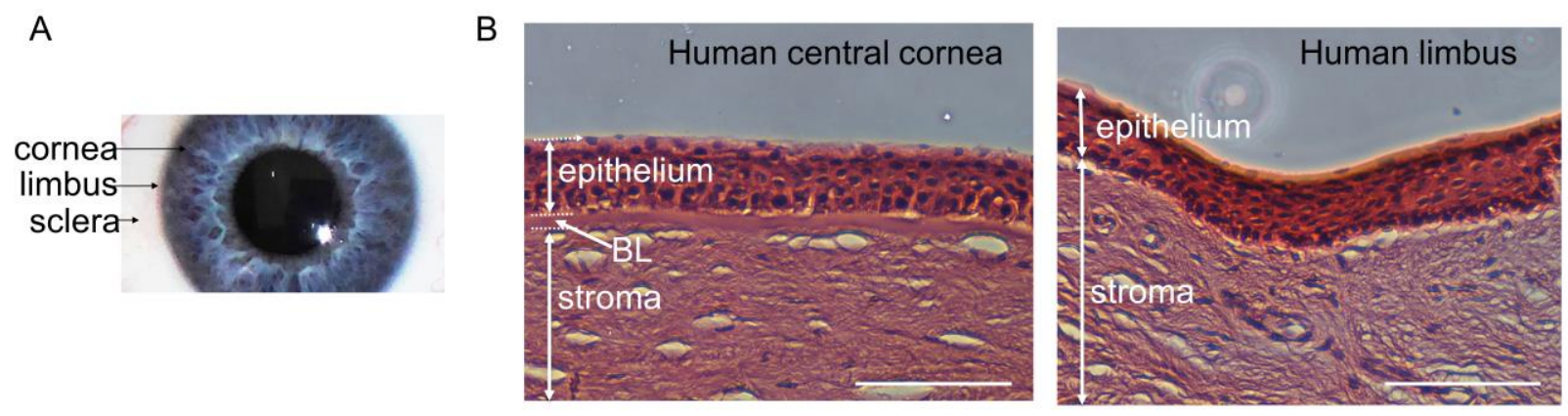

C

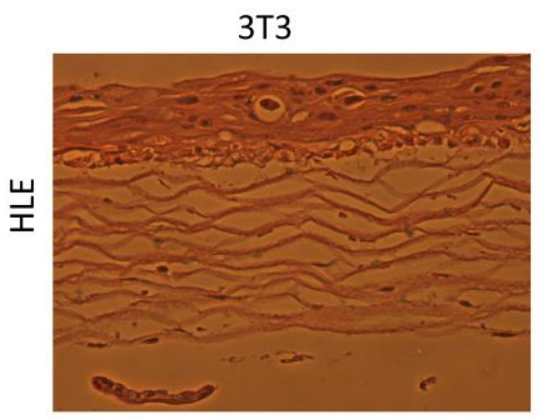

HLF

HOMF
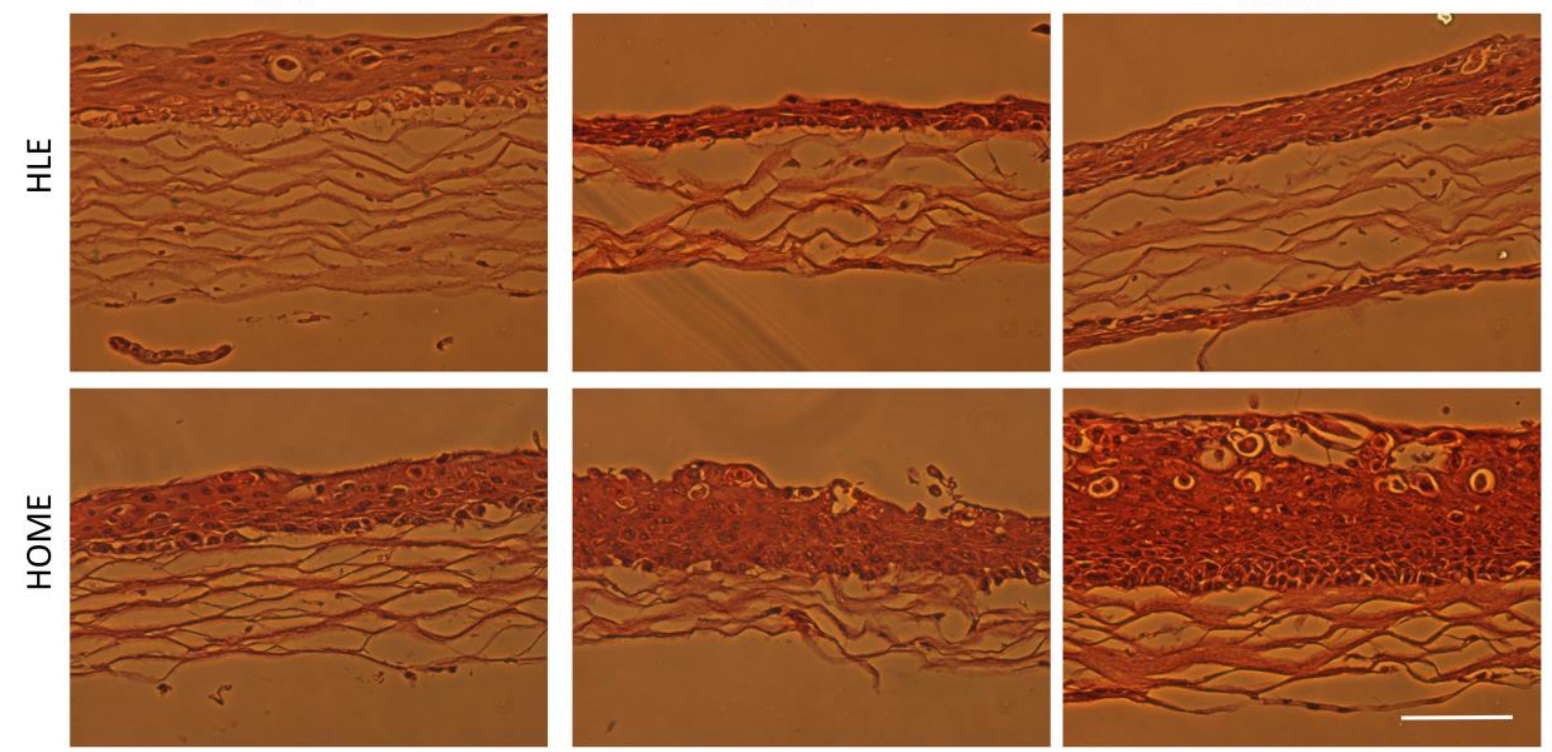

D

E
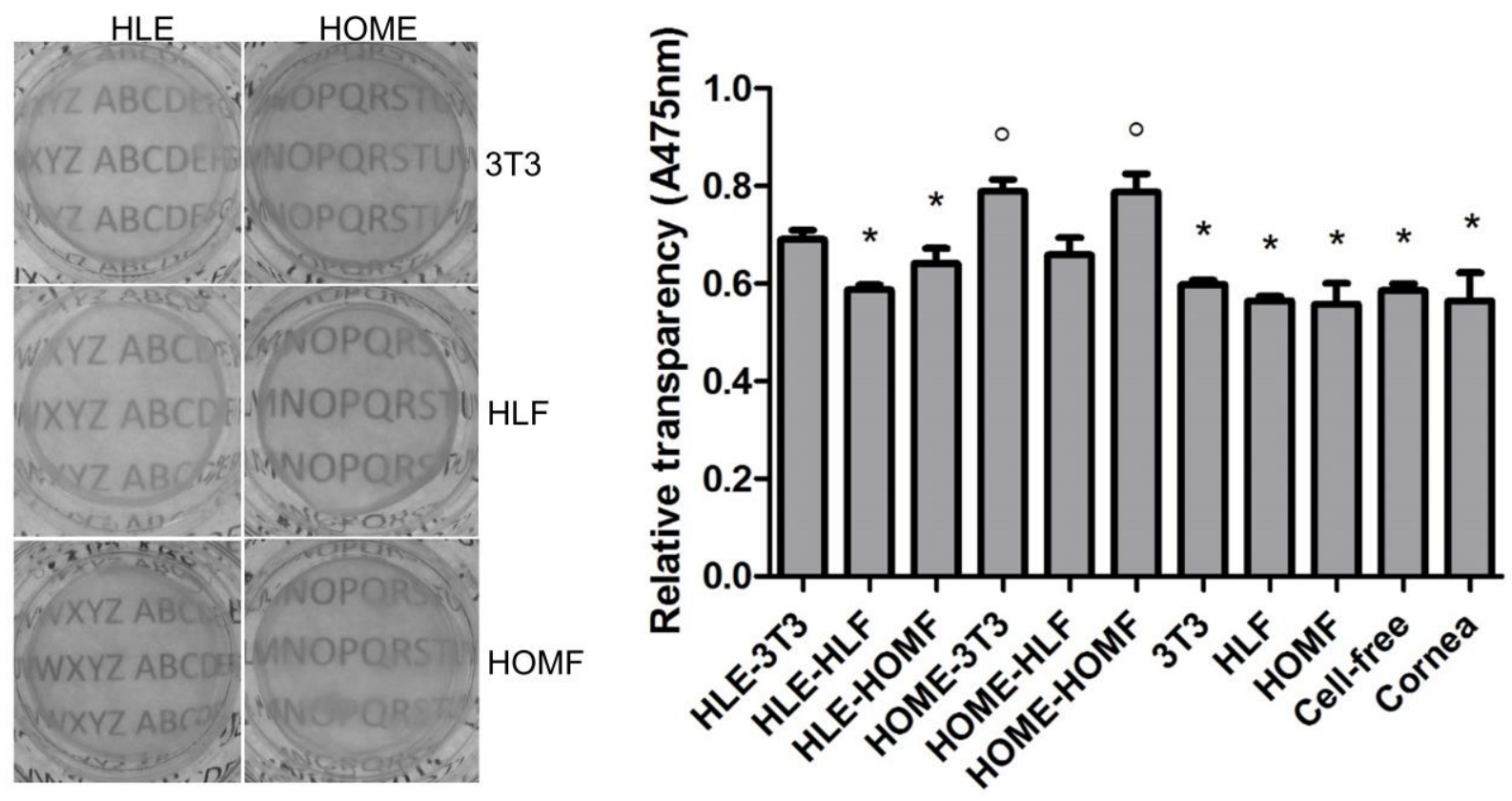
Figure 2. Multi-layered epithelium, and transparency of the tissue equivalents. A. The corneal limbus is located between the sclera and cornea. B\&C. H\&E images show that all tissue equivalents and cornea controls had a multi-layered epithelium. BL indicates the Bowman's layer which is present in the human central cornea but not in the limbus. Scale bars: $100 \mu \mathrm{m}$. D. Printed alphabet letters could be observed through all the epithelial-fibroblast tissue equivalents by eye. HOMEHOMF: oral mucosa tissue equivalent, HLE-HOMF: cornea-oral tissue equivalent. E. Transparency measurements at A475nm showed that although oral mucosal tissue equivalents (HOME-HOMF) were less transparent than corneal tissue equivalents (HLE-HLF), they did not differ significantly in transparency to HOME controls with HLF or 3T3s (HOME-HLF and HOME-3T3) or to HLE$3 \mathrm{~T} 3{ }^{*} \mathrm{P}<0.05$ compared to oral mucosal tissue equivalents, HOME-HOMF (one way ANOVA). Cornea-oral hybrid tissue equivalents (HLE-HOMF) did not differ in transparency to cornea tissue equivalents (HLE-HLF) or HLE controls with 3T3s (HLE-3T3), fibroblast only tissue equivalents or human cornea. Data shown are mean $\pm \mathrm{SD} .{ }^{\circ} \mathrm{P}<0.05$ compared to cornea-oral hybrid tissue equivalents, HLE-HOMF (one way ANOVA).

\subsection{Transparency of tissue equivalents}

Letters of the alphabet printed on white paper could be observed through all RAFT tissue equivalents by eye (Figure 2D). The transparency (absorbance at $475 \mathrm{~nm}$ ) of tissue equivalents (epithelial-fibroblast) with HLE or HOME was not significantly affected by fibroblast type.

Cornea-oral hybrid tissue equivalents did not differ significantly in transparency to HLE controls with HOMF replaced by $3 \mathrm{~T} 3$ or HLF, or to human cornea controls (Figure $2 \mathrm{E}, \mathrm{P}>0.05$ ).

The transparency of oral mucosal tissue equivalents was comparable to HOME controls with HLF or 3T3s instead of HOMF (Figure 2E, P>0.05). When oral mucosal tissue equivalents were 
compared to human cornea controls and HLE-fibroblast tissue equivalents, some differences in transparency were observed (Figure 2E). In order to determine whether these differences in transparency were due to the different fibroblast types in the collagen or their effect on the epithelial cells, the transparency of the epithelial-fibroblast constructs was compared to fibroblast only constructs cultured for the same length of time. HLF, HOMF and 3T3 only RAFT did not differ significantly in transparency. However some differences in transparency were observed between HOME-fibroblast and fibroblast only RAFT. Oral mucosal tissue equivalents and HOMF only RAFT $(\mathrm{P}<0.001)$ were significantly different (Figure 2E) as were HOME controls with 3T3s and 3 T3 only RAFT $(\mathrm{P}<0.01)$ (not indicated in Figure 2). Interestingly, there was no significant difference in transparency between HOME controls with HLF and HLF only RAFT. HOME controls with HLF were also not significantly different to any of the HLE-fibroblast constructs.

\subsection{Marker expression in the tissue equivalents}

The putative stem cell marker p63 $\alpha$ was expressed in the basal layers of all HOME-fibroblast and HLE-fibroblast tissue equivalents similar to the human cornea (Figure 3, A and B). PAX6, CK12, and MUC16 which are expressed in the corneal epithelium were investigated to see if using HOMF altered the expression of these corneal markers in the tissue equivalents compared to controls with HLF or 3T3s.

HLE-fibroblast tissue equivalents had a similar pattern of expression of p63 $\alpha$, PAX6, and MUC16 in the epithelial cells to human cornea as detected by immunohistochemistry (Figure 3 and Figure 4) regardless of the fibroblast type used (HOMF, HLF or 3T3s). Expression of these markers in HLE was confirmed by PCR and western blotting (Figure 5). CK12 was also detected in all HLEfibroblast constructs by PCR (Figure 5).

Irrespective of the type of support fibroblast used, p63 $\alpha$ and PAX6 (Figure 3-5) were detected in HOME in all the tissue equivalents, as was low expression of MUC16 (Figure 3 and 5). In this 
study no CK12 was detected in the epithelial cells in HOME-fibroblast tissue equivalents by PCR (Figure 5A). The oral mucosal tissue equivalents therefore had a different marker profile in the epithelial cells (lower MUC16, no CK12) when compared to HLE-fibroblast tissue equivalents or human cornea.

PAX6 was observed in all HLE-fibroblast and HOME-fibroblast constructs by PCR, immunohistochemistry and western blotting (Figure 4 and 5). Since other studies have used cultured HOME as a negative control for PAX6 ${ }^{[21,22]}$, or found no PAX6 expression in cultured HOME $^{[23]}$ we checked to see if PAX6 was present in oral mucosal tissue. PAX6 was observed in some areas of a human buccal oral mucosa biopsy (Figure 4B). In contrast to the nuclear PAX6 observed in the human corneal epithelium, in the oral mucosa PAX6 was localised to the cytoplasm. In all HLE-fibroblast constructs nuclear PAX6 was observed similar to that in the cornea, whereas in the HOME-fibroblast constructs HOME expressed PAX6 predominantly in the cytoplasm, although nuclear expression was also observed in some areas. 
A. Human cornea

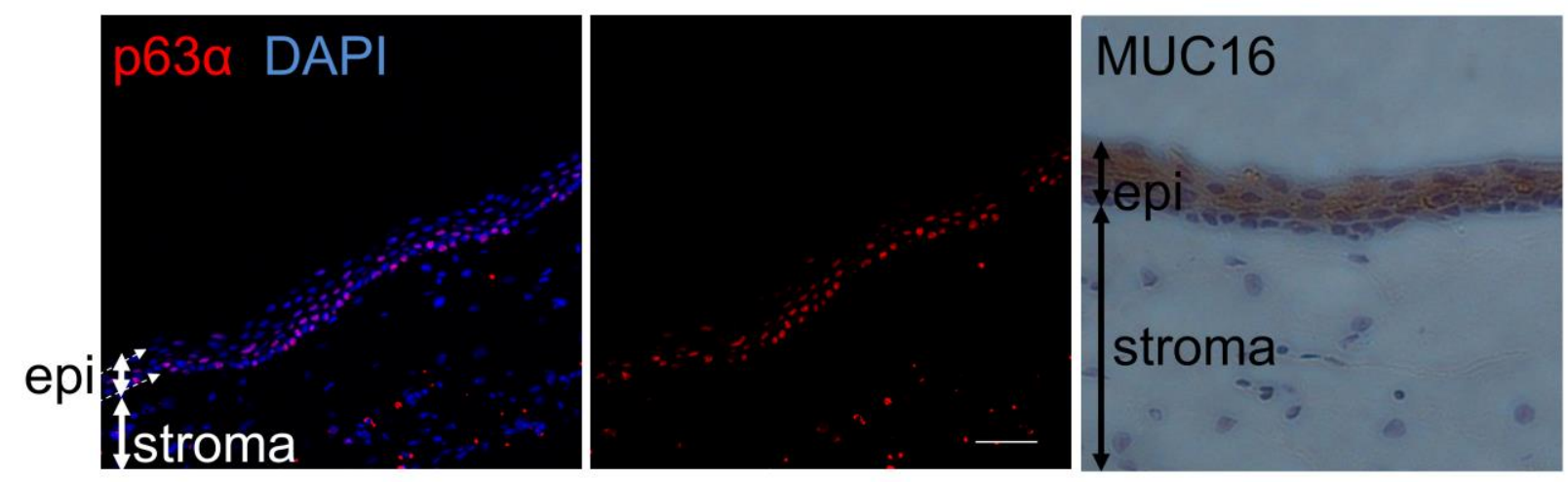

B. RAFT tissue equivalents $p 63 a$

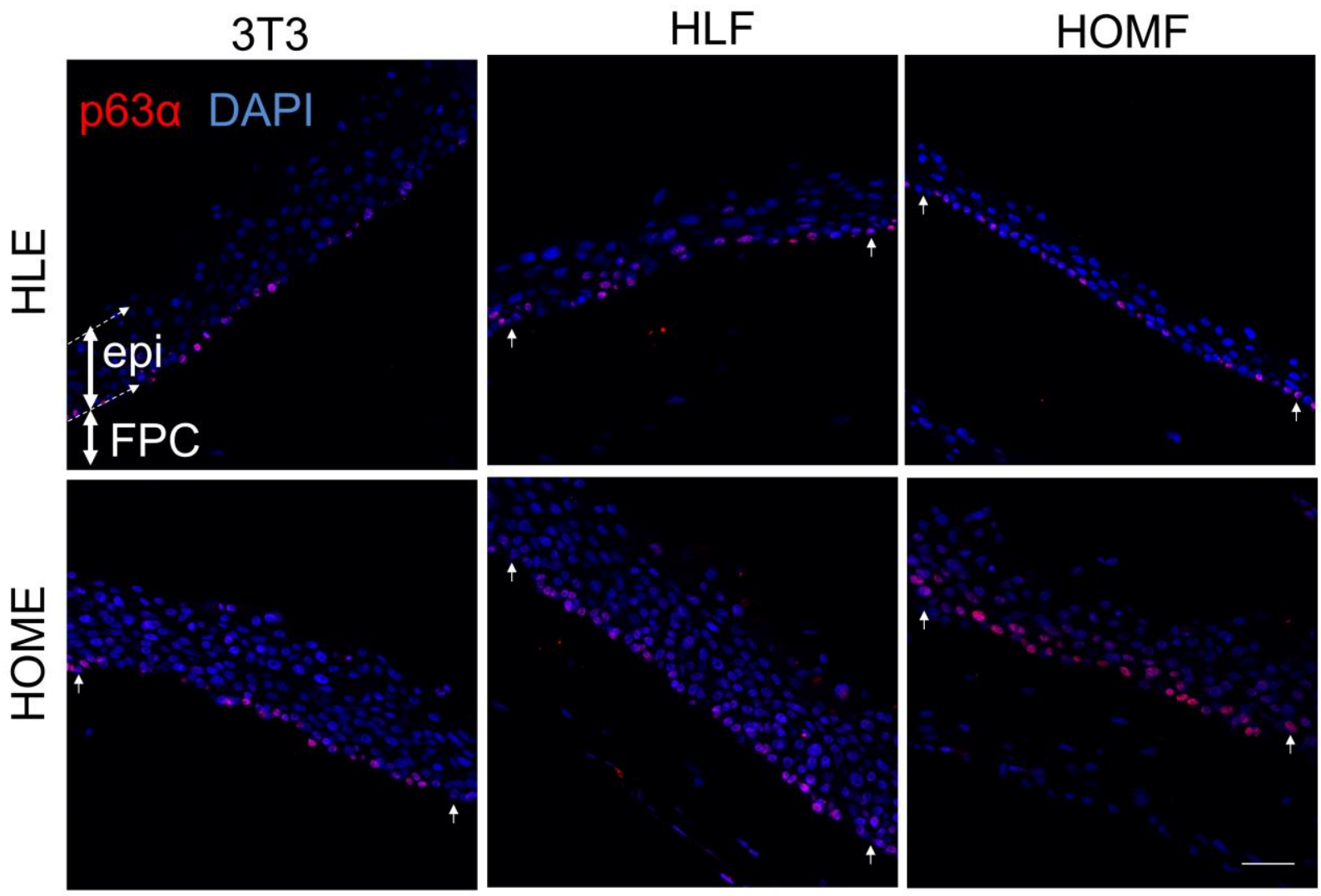

C. RAFT tissue equivalents MUC16

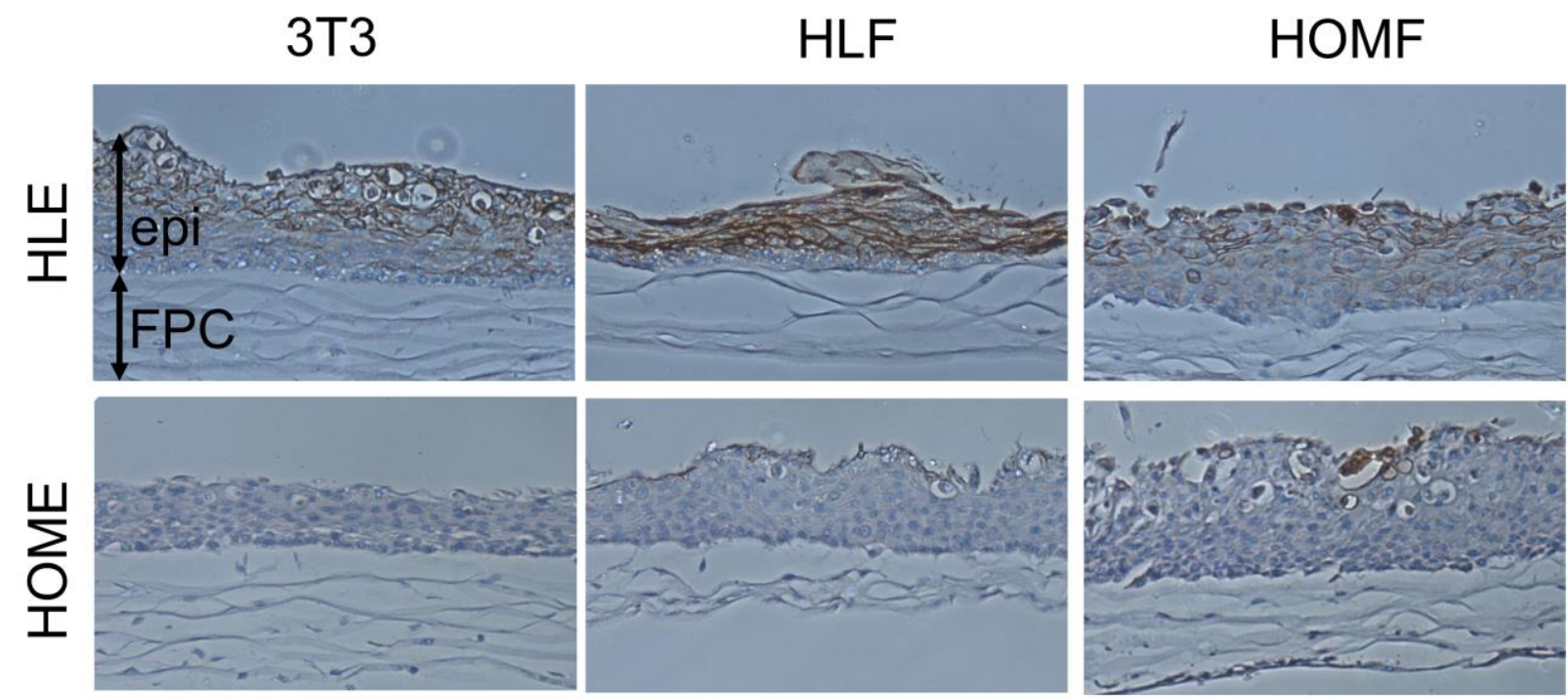


Figure 3: p63 $\alpha$ and MUC16 expression in human cornea and tissue equivalents with limbal or oral epithelial cells and the following fibroblast types: HOMF, HLF, or 3T3s. A. p63 $\alpha$ and MUC16 were observed in the human cornea. p63 $\alpha$ was observed predominantly in the basal epithelial cells. B. p63 $\alpha$ was observed in the basal epithelial layer of all epithelial-fibroblast tissue equivalents. The basal epithelium is indicated by arrows. C. MUC16 was expressed in all HLEfibroblast tissue equivalents. Scale bars are 50 $\mu \mathrm{m}$. FPC: fibroblast populated collagen, epi: epithelium, HOME-HOMF: oral mucosal tissue equivalent, HLE-HOMF: cornea-oral tissue equivalent. 
A. Human cornea

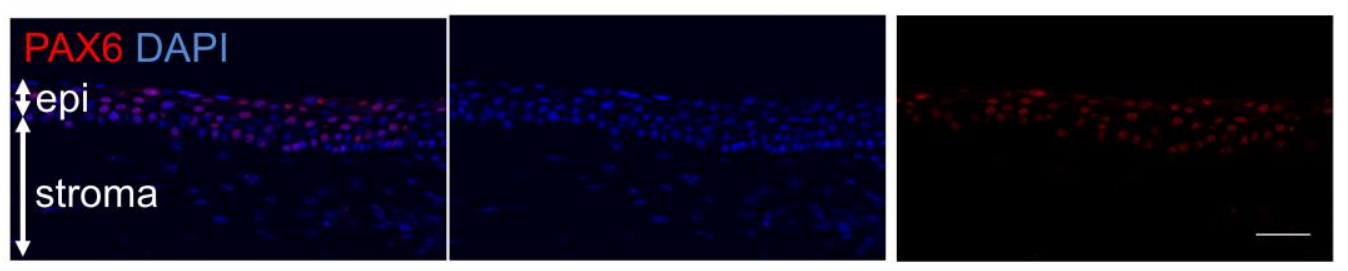

B. Human buccal oral mucosa

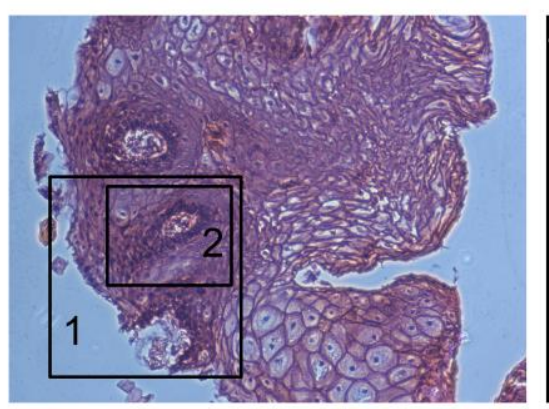

1 PAX6 DAPI

2 PAX6 DAP
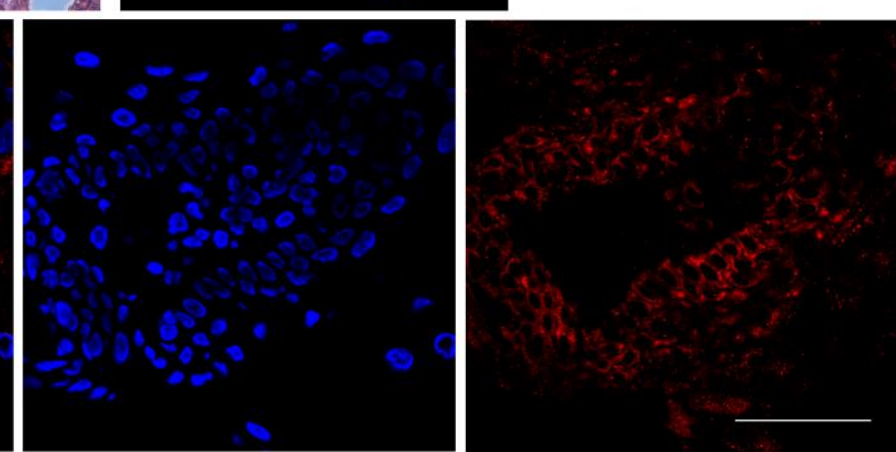

C.RAFT tissue equivalents

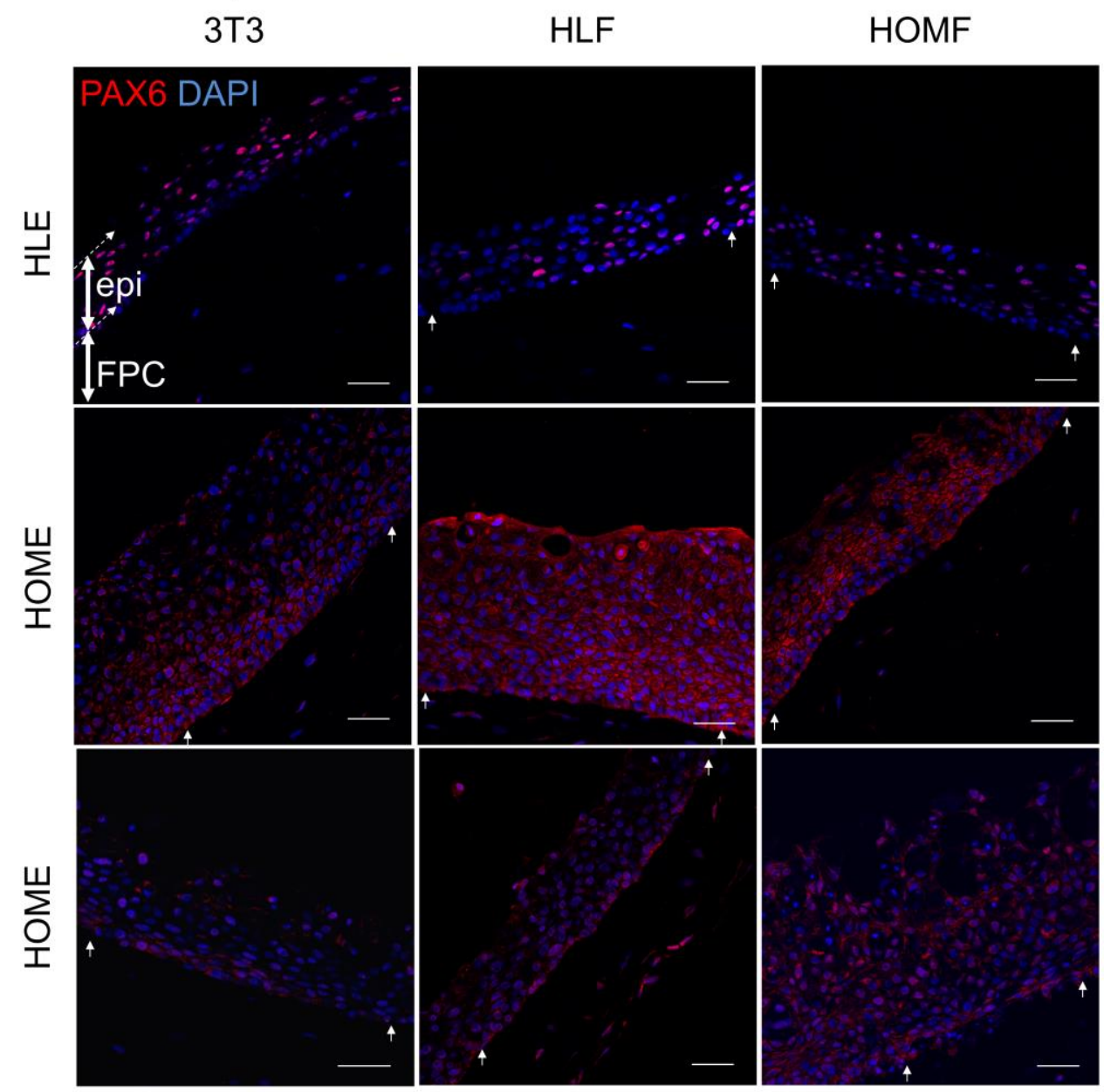


Figure 4: PAX6 expression was detected by immunohistochemistry in human tissue and tissue equivalents with limbal or oral epithelial cells and the following fibroblast types: HOMF, HLF, or 3T3s. PAX6 was detected in human cornea, human buccal oral mucosa, and epithelial cells (HLE and HOME) in the RAFT tissue equivalents. A. Nuclear PAX6 was observed in corneal epithelial cells of the human cornea. B. PAX6 was observed in the cytoplasm of some epithelial cells in the human buccal oral mucosa. The basal epithelium is indicated by arrows. C. Nuclear PAX6 was observed in epithelial cells in all HLE-fibroblast tissue equivalents in a similar location and distribution throughout all epithelial layers to that found in the cornea. Epithelial cells in HOME-fibroblast tissue equivalents expressed PAX6 predominantly in the cytoplasm (middle row of panel). However, some areas also showed nuclear PAX6 localisation (bottom row of panel). All scale bars are 50 $\mu \mathrm{m}$. FPC: fibroblast populated collagen, epi: epithelium, HOME-HOMF: oral mucosal tissue equivalent, HLE-HOMF: cornea-oral tissue equivalent. 
A. PCR

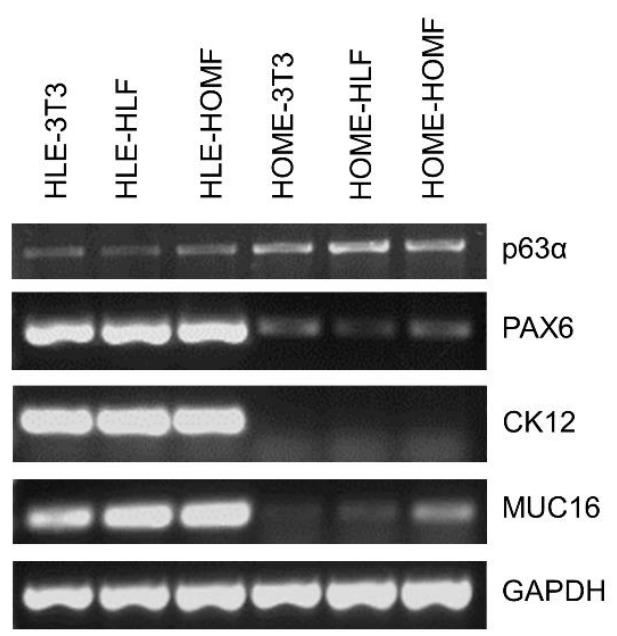

B. Western blot

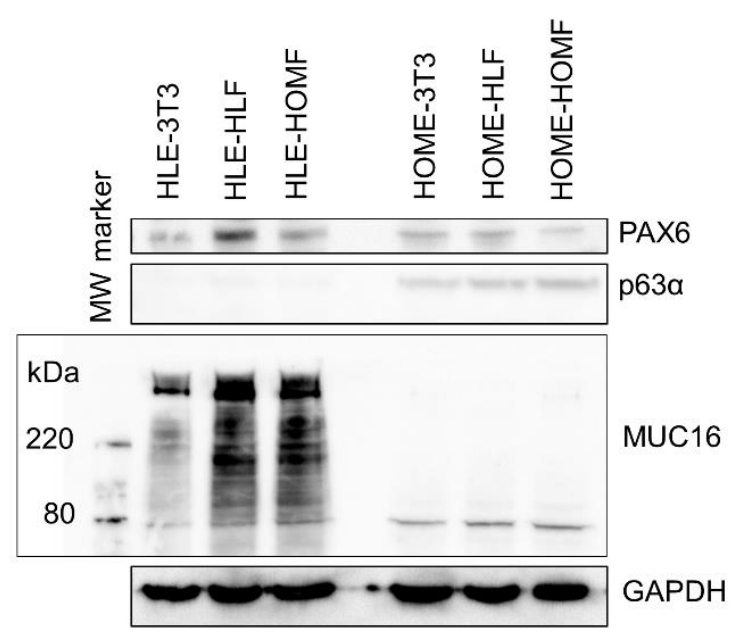

C. Western quantification
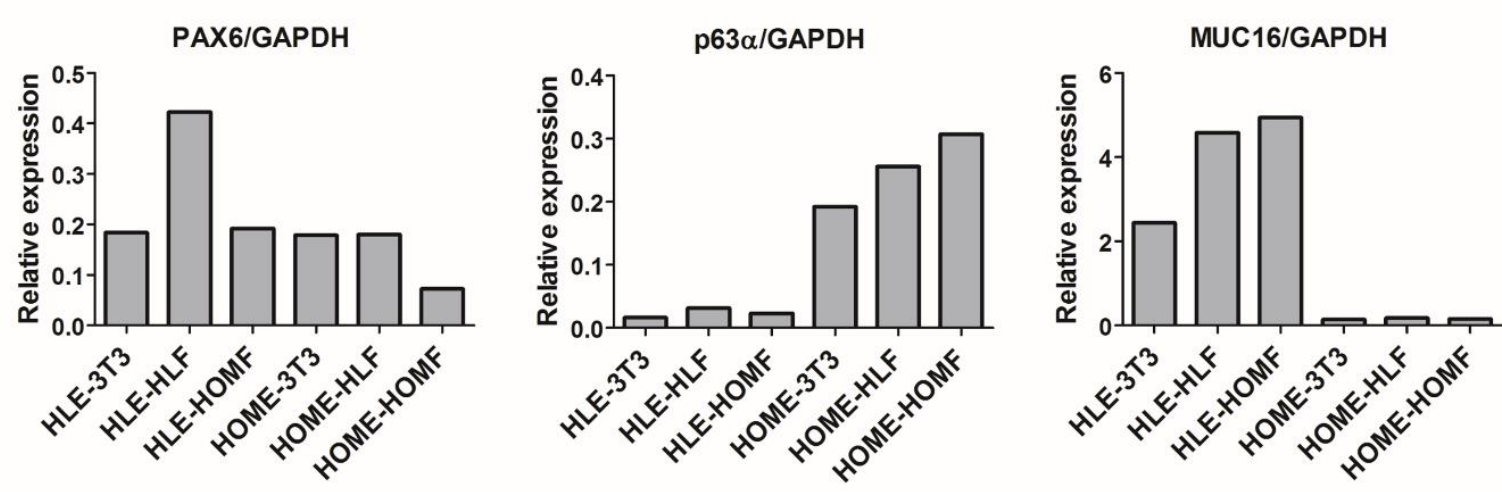

Figure 5: Marker expression of epithelial cells in the tissue equivalents. A. PCR. Expression of p63a, PAX6, CK12, and MUC16 in epithelial cells (passage 1 HLE and passage 2 HOME) supported by the following fibroblast types: 3 T3, HLF, and HOMF in the tissue equivalents. p63 $\alpha$ was expressed in all the tissue equivalents. PAX6, CK12, and MUC16 were expressed in all HLEfibroblast tissue equivalents. Low expression of PAX6 and MUC16 was observed in HOMEfibroblast tissue equivalents. No CK12 was detected in HOME-fibroblast tissue equivalents. $n=1 *$. B. Western blot bands obtained. A range of bands was obtained for MUC16 starting at approximately 80kDa. C. Relative expression of p63a, PAX6, and MUC16 protein in HLE and HOME normalised to GAPDH in the 3D constructs. $N=1 *$ * Same donor cells for PCR and Western blotting for HOME (1 donor eye) and HLE (2 eyes from the same donor, one for PCR 
experiment, and one for western blotting). Epithelial cells were pooled from at least 3 replicate gels per epithelial-fibroblast combination). HOME-HOMF: oral mucosal tissue equivalent, HLEHOMF: cornea-oral tissue equivalent.

\subsection{Oral mucosal and corneal-oral hybrid tissue equivalents have a similar ultrastructure to} the cornea

All epithelial-fibroblast constructs had similar features to the human cornea: SEM showed that the uppermost epithelial cells in all HLE-fibroblast and HOME-fibroblast tissue equivalents had multiple microvilli on their surface (Figure 6), and TEM showed that in all constructs there were squamous cells in the top layers of epithelium, and small round cells with a more stem cell like phenotype in the basal layer (Figure 7). TEM also revealed either close association or direct interaction between basal epithelial cells and fibroblasts in all the epithelial-fibroblast combinations (Figure 7). 


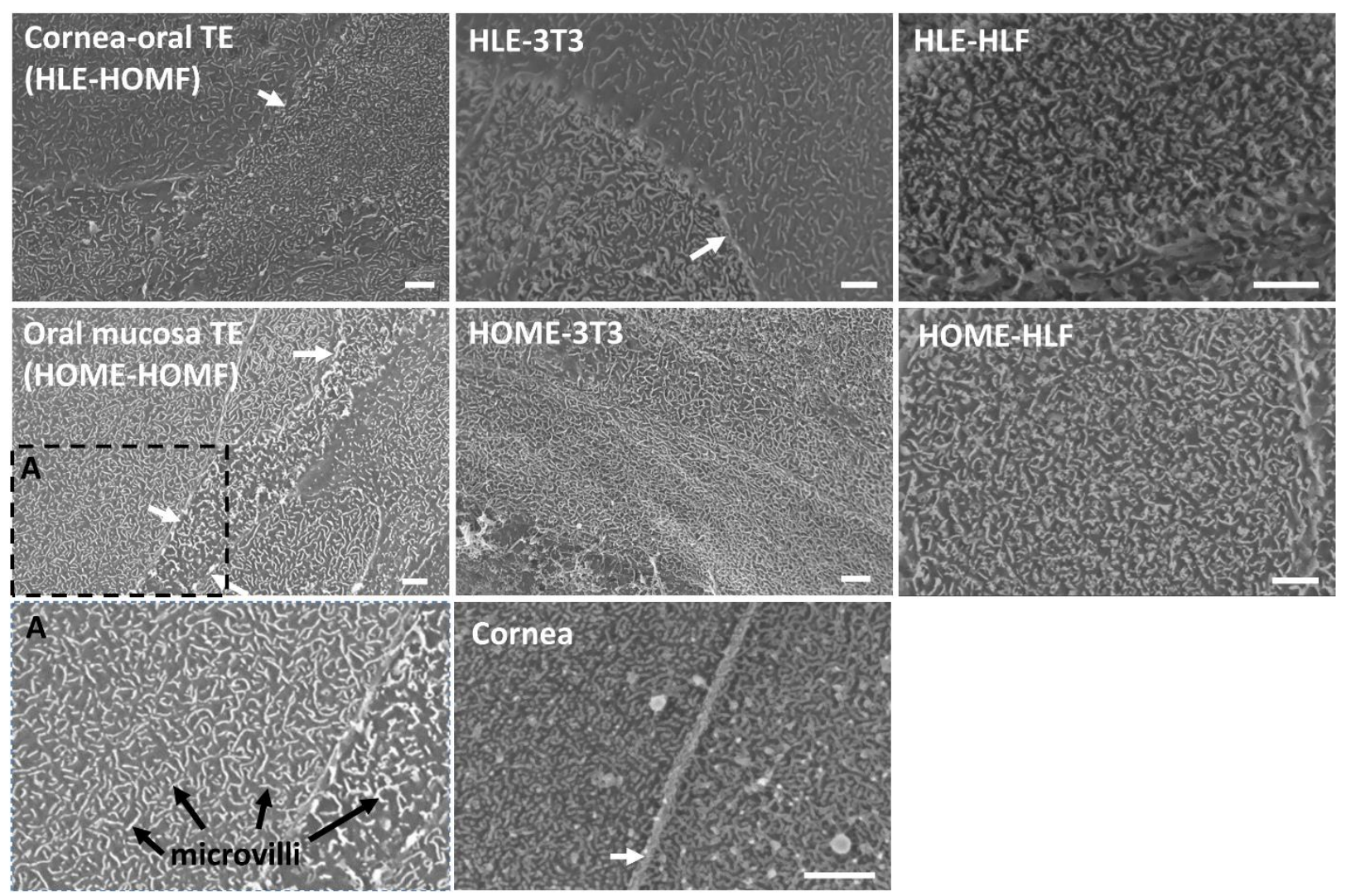

Figure 6: Microvilli on the surface of the superficial epithelial cells in oral mucosa tissue equivalents,

cornea-oral tissue equivalents, and controls. SEM images showed that the superficial epithelial cells in all the tissue equivalents had multiple microvilli on their surface similar to that observed in in vivo human corneal epithelium. Scale bars are 2 micron. TE: tissue equivalent. White arrows indicate the border between neighbouring cells. 


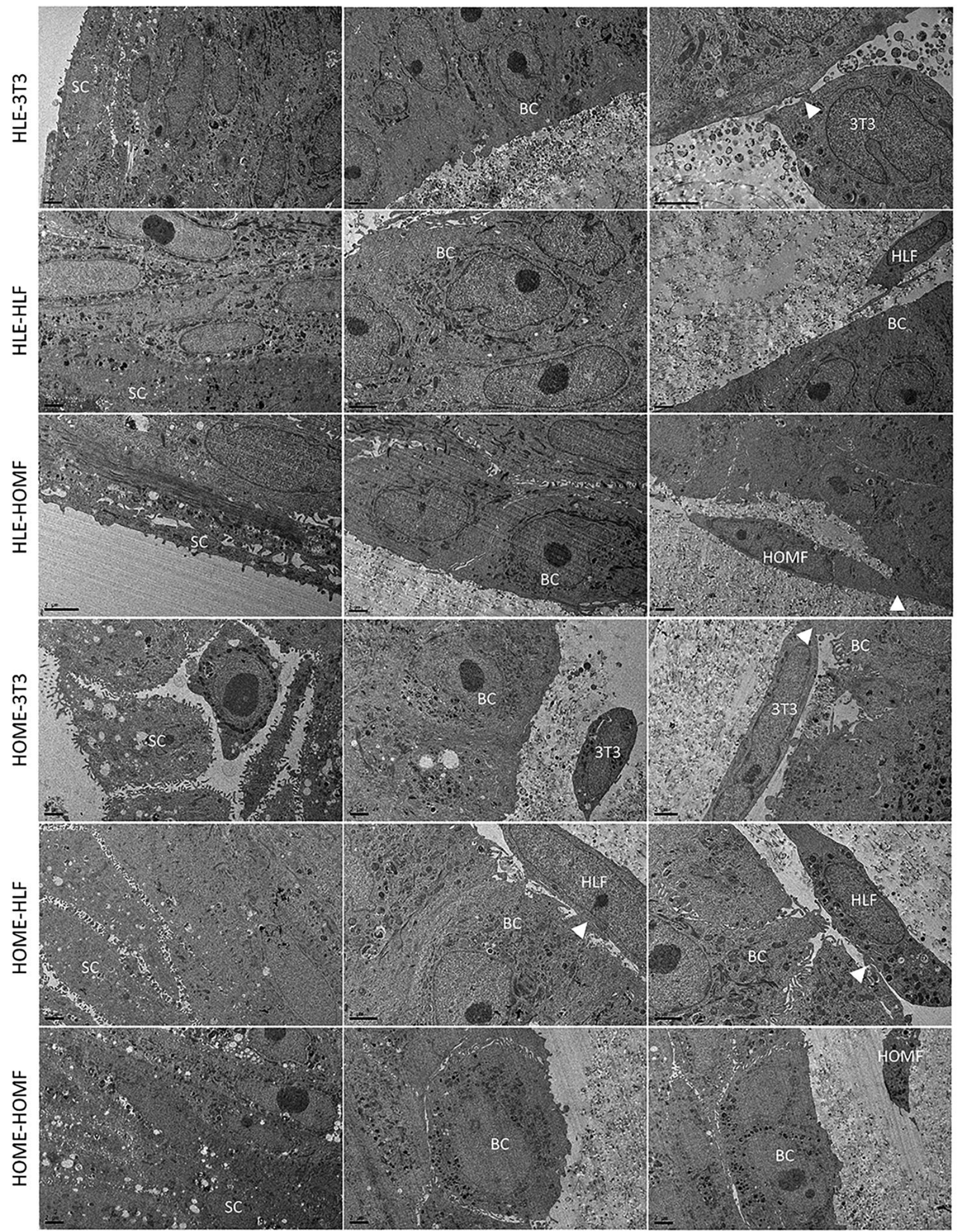

Figure 7. TEM images of epithelial cells and epithelial-fibroblast interactions in oral mucosal and corneaoral tissue equivalents, and epithelial-3T3 and epithelial-HLF controls. The first column of images is of the 
top stratified layers with squamous cells labelled as SC. The second column is of cells in the basal layer (basal cells labelled as BC) with small round cells with a more stem cell like phenotype. The third column shows the interaction between epithelial cells and fibroblasts. Direct contacts were observed between basal cells and fibroblasts and are indicated with arrows. Scale bars are 2micron. HOME-HOMF: oral mucosal tissue equivalent, HLE-HOMF: cornea-oral tissue equivalent.

\section{Discussion}

The RAFT process of producing plastic compressed collagen tissue equivalents has been developed with GMP compliance in mind ${ }^{[13]}$ (process now further adapted from that used in this study) and provides a reproducible substrate for cell culture. By incorporating fibroblasts into collagen based RAFT, the substrate mimics the cell populated stroma found in the limbus, on top of which a multilayered epithelium can be cultured to produce a tissue equivalent. All HOME-fibroblast and HLEfibroblast tissue equivalents had a multi-layered epithelium and epithelial organisation similar to the human cornea with small stem cell like cells in the basal layer and squamous cells with multiple microvilli on their surface in the superficial epithelial layer. Direct interaction was observed between some basal epithelial cells and fibroblasts in the RAFT substrate mimicking the interactions observed in the limbus between putative LESC and limbal stromal cells. ${ }^{[17]}$ These interactions may be useful for improved culture success. In addition to use in the treatment of LSCD, epithelial-fibroblast RAFT tissue equivalents may be a useful model for studying the interactions and communication between epithelial and stromal cells in the limbus or possibly other stem cell niches. RAFT has previously been used to create tissue equivalents with bioengineered limbal crypts mimicking the limbal crypts found in the human cornea where LESC reside. ${ }^{[24]}$

HOME and HOMF can be easily isolated from a small oral mucosal biopsy taken from the patient and therefore autologous. We have previously shown that HOMF are comparable to 3T3s as a 
feeder fibroblast for the culture of epithelial cells (HOME and HLE) in a 2D co-culture system. ${ }^{\text {[20] }}$ Here we have shown that HOMF can also be used as an autologous alternative to $3 \mathrm{~T} 3 \mathrm{~s}$ in the $3 \mathrm{D}$ RAFT system to support the culture of HOME and HLE, thus removing murine 3T3s from the culture process but still allowing important epithelial-fibroblast interactions. In other studies human dermal fibroblasts have also been shown to support HOME culture. ${ }^{[25,26]}$ Autologous fibroblasts may therefore be used as $3 \mathrm{~T} 3$ alternatives in the future for the culture of epithelial cells for clinical use in the treatment of LSCD. It is important to make a cell therapy as safe as possible and although there is no evidence to suggest that 3T3s have had any adverse effect from their use in graft production, ${ }^{[27]}$ removal of these cells from the culture system would eliminate any risk of murine viral transmission to human cells. There are two main methods of obtaining epithelial cells from limbal/oral biopsies for the treatment of LSCD, either by explant culture or using enzymes such as Dispase to produce a single cell suspension (as in this study) which is then cultured on the substrate of choice. For COMET, nearly all clinical studies have used the single cell suspension method together with 3T3s. Although feeder-free culture methods have been investigated for the production of epithelial cells for use in the treatment of LSCD, 3T3s have been shown to be beneficial for HLE culture with direct contact between HLE and 3T3s being important for the initiation of epithelial colonies for the single cell suspension method, ${ }^{[28]}$ and a combination of direct and indirect contact better for producing more progenitor cells than either direct or indirect contact. ${ }^{[28]}$ In the culture method used here, epithelial cells had direct contact with fibroblasts on the RAFT surface to produce a monolayer and then these cells continued to receive support from the fibroblasts inside the collagen (via direct and indirect contact) for continued culture and stratification.

In addition to the use of oral mucosal cells (epithelial and fibroblast), the culture method used here is different to that previously described ${ }^{[15,16,29]}$ in that the epithelial cells were co-cultured with fibroblasts on the RAFT surface rather than seeding epithelial cells only on top. Reasons for the method used here include: fewer epithelial cells were required per tissue equivalent, and an 
increased opportunity for interaction between the epithelial and fibroblast cells. Using fewer epithelial cells per graft offers the opportunity for spare cells for uses such as: a backup graft, cells to be cryopreserved for use in future treatment if required, and cells for quality control testing prior to release.

Comparison of HOME-fibroblast and fibroblast only RAFT suggested that the differences in transparency observed were due to the effect of the fibroblasts on the HOME cells rather than the transparency of the fibroblasts themselves in the collagen. This comparison indicated that HLF may be useful for improved transparency of HOME-fibroblast populated RAFT compared to HOMF or 3T3s. It may be possible to modify the culture process to improve transparency for example by decreasing the time in culture, or by aligning the fibroblasts in the collagen. However the transparency of tissue equivalents (epithelial-fibroblast) with HLE or HOME was not significantly affected by fibroblast type. Furthermore such modifications may not be necessary as it is anticipated that RAFT will be degraded/remodelled once transplanted onto the eye. RAFT tissue equivalents have been shown to have comparable rates of degradation to amniotic membrane in vitro. ${ }^{[30]}$

It is possible that further changes may occur following transplantation of these tissue equivalents onto the eye as tissue specific environment has been shown to influence cell fate. ${ }^{[31]}$ Various stem cells have been directed towards a more corneal like phenotype using conditions that mimic those found in the in vivo LESC niche, ${ }^{[32-35]}$ or by transplanting these cells onto corneas. ${ }^{[36,37]}$ Several papers used conditioned media from HLF (in combination with extracellular matrix). ${ }^{[33,34]}$ It is therefore possible that existing corneal stroma and/or stromal cells may direct HOME to become more corneal like post-transplantation. HOME populated tissue equivalents in our study did not express CK12 regardless of the supporting fibroblast type (HOMF, HLF, or 3T3), and all expressed PAX6 and MUC16. This suggests that in the culture system described here either more than just fibroblast type is required to direct HOME towards a more corneal phenotype or HLF are not the 
best cell type to use for this purpose. Human corneal stromal stem cells for example have been shown to be better than human corneal fibroblasts for generating corneal stromal tissue equivalents with more organised collagen fibrils and more abundant cornea specific extracellular matrix components. ${ }^{[38]}$ It has been shown that HOME transplanted onto the eye during COMET can acquire an ocular phenotype particularly in the basal epithelial cells where PAX6 and CK12 were upregulated. ${ }^{[39]}$ It may therefore not be so important to acquire a corneal phenotype prior to transplantation, as the corneal microenvironment in vivo may be better for inducing a more corneal phenotype than fibroblast type in vitro.

Here we have shown PAX6 expression in the cell cytoplasm in some areas of a human buccal oral mucosal biopsy. Another study has also detected PAX6 in human oral mucosal tissue, ${ }^{[39]}$ although this staining was pan-nuclear. PAX6 is highly expressed in the corneal epithelium and decreased PAX6 has been associated with severe ocular surface disorders such as Aniridia, Chemical burn and Stevens Johnson Syndrome. ${ }^{[22]}$ Since PAX6 is expressed in the oral mucosal epithelium, HOME should have the potential to express PAX6 in culture. Although several studies have found cultured HOME to be PAX6 negative, ${ }^{[21-23]}$ we have previously shown PAX6 expression in cultured HOME when using a 2D direct contact co-culture method with 3T3s, HLF, or HOMF. ${ }^{[20]}$ Cultured HOME can also express PAX6 when cultured as described here on 3D RAFT tissue equivalents with feeder fibroblasts and this culture method may therefore be useful for producing HOME cells for ocular surface repair.

In this study the putative stem cell marker p63 $\alpha$ was detected in the basal epithelial layer in both oral mucosal tissue equivalents and cornea-oral tissue equivalents. The percentage of p63-bright cells in the tissue equivalents could be assessed in future work as this has been shown to positively correlate with transplantation success for limbal stem cell grafts. ${ }^{[40]}$ 
In this study primary epithelial expansion was performed on 3T3s prior to seeding onto RAFT. The culture method used here could be adapted to completely remove $3 \mathrm{~T} 3 \mathrm{~s}$ from the culture process by either eliminating the primary expansion step, or using autologous feeder fibroblasts (HOMF or HLF) for primary expansion. Pre-expansion of epithelial cells on 3T3s is commonly performed prior to graft production for cultured LESC therapy. It is possible that pre-expansion on HOMF may produce greater differences in corneal phenotype compared to HLF or 3T3s as the HOMF would have an increased opportunity to influence the epithelial phenotype. However there are advantages of having a pre-expansion step such as spare cells for testing. The culture method described here could also be adapted to further eliminate animal-derived products from the culture system, for example by using autologous serum instead of bovine serum. Autologous serum has been shown to be a suitable alternative to bovine serum for the culture of HLE and HOME and has been used for the culture of these cells for clinical application in the treatment of LSCD (HOME, ${ }^{[23,}$ $\left.{ }^{41-43]} \operatorname{HLE}^{[44-49]}\right)$.

\section{Conclusion. ${ }^{[40]}$}

Here we have shown an alternative culture method for producing autologous epithelial cells for potential application in the treatment of LSCD. HOME and HLE were successfully cultured on RAFT using HOMF as a feeder fibroblast to produce tissue equivalents with features of the corneal epithelium: a multi-layered epithelium with p63 $\alpha$ expression in the basal epithelial layer, squamous cells in the top layers of epithelium with multiple microvilli on their surface, small round cells with a more stem cell like phenotype in the basal layer, and PAX6 expression. A close interaction was observed between the fibroblasts and basal epithelial cells similar to that found in the human limbus. 
Ideally cell therapies should be autologous and produced using a fully defined cell culture system free of any animal derived products from a patient safety perspective. The typical culture method for HOME for use clinically in COMET for the treatment of LSCD uses amniotic membrane as a culture substrate and murine 3T3s as a feeder fibroblast. Here RAFT was used as a reproducible cell substrate and HOMF as an alternative and autologous feeder fibroblast to murine $3 \mathrm{~T} 3 \mathrm{~s}$. Oral mucosal tissue equivalents (for bilateral LSCD) and corneal-oral tissue equivalents (for unilateral LSCD) offer the opportunity for an autologous graft without the need for immunosuppression to prevent graft rejection. In addition, cornea-oral hybrid tissue equivalents offer an alternative autologous graft to corneal tissue equivalents (populated with HLE and HLF) for the treatment of unilateral LSCD.

In addition to potential use in the treatment of LSCD, RAFT tissue equivalents may also be a useful model for studying epithelial-stromal cell interactions in the limbus or possibly other stem cell niches.

\section{Experimental section}

\subsection{Donor tissue}

Cadaveric limbal rims were obtained from the Moorfields Lions Eye Bank (London, UK) or the Lions Institute Eye Bank (Miami, Florida, US). Buccal oral mucosal biopsies were taken from healthy volunteers as previously described. ${ }^{[20]}$ All tissue had appropriate research consent and ethics approval (reference number: 09/H0721/50). 


\subsection{Human epithelial cell isolation and culture}

HLE and HOME were isolated as previously described, ${ }^{[20]}$ HLE from cadaveric limbal rims, and HOME from human buccal oral mucosal biopsies. These cells were suspended in Corneal Epithelial Culture Medium (CECM) ${ }^{[20]}$ and seeded onto growth arrested 3T3s $\left(2.7 \times 10^{4}\right.$ cells cm$\left.^{-2}\right)$ in a T25 tissue culture flask. Cells were cultured in the presence of $5 \% \mathrm{CO}_{2}$ in air at $37^{\circ} \mathrm{C}$. Culture medium was changed three times a week and primary HLE and HOME were cryopreserved in 70\% CECM (without EGF) plus 20\% FBS plus 10\% DMSO prior to confluency.

\subsection{Human fibroblast isolation and culture}

Following isolation of epithelial cells, HLF and HOMF were isolated by explant culture from the remaining limbal rims, or oral mucosal biopsies. These fibroblasts were cultured in DMEM + glutamax plus 10\% FBS and 1x antibiotic-antimycotic (Life Technologies). Cells were passaged at a ratio of 1:3 when subconfluent. HLF and HOMF were used at passage number 5 or 6 .

\subsection{Growth arrest of fibroblasts}

3T3s, HLF and HOMF were growth arrested with Mitomycin C (MMC) (Movianto or Sigma) as previously described: ${ }^{[20]}$ MMC $\left(10 \mu \mathrm{g} \mathrm{ml}^{-1}\right)$ was added for 3 hours to HLF and HOMF, and MMC $\left(4 \mu \mathrm{g} \mathrm{ml}^{-1}\right)$ was added for 2 hours to $3 \mathrm{~T} 3 \mathrm{~s}$.

\subsection{Preparation of RAFT tissue equivalents}

RAFT tissue equivalents described in Table 1 were produced. The aim was to produce a tissue equivalent consisting of a multi-layered epithelium on a fibroblast populated collagen stromal equivalent. For each epithelial donor (HLE or HOME) the following tissue equivalents were set up: epithelial-3T3, epithelial-HLF, and epithelial-HOMF. 


\begin{tabular}{|l|c|c|c|}
\hline \multirow{2}{*}{ Tissue equivalent } & Cell types used & Unilateral LSCD & Bilateral LSCD \\
& (epithelial-fibroblast) & & \\
\hline Oral mucosa & HOME-HOMF & Yes & Yes \\
\hline Cornea-oral hybrid & HLE-HOMF & Yes & No \\
\hline HOME controls & HOME-3T3 & No & No \\
\cline { 2 - 4 } & HOME-HLF & Yes & No \\
\hline HLE controls & HLE-3T3 & No & No \\
\cline { 2 - 4 } & HLE-HLF* & Yes & \\
\hline
\end{tabular}

Table 1. RAFT tissue equivalents investigated in this study and which epithelial-fibroblast combinations could produce autologous grafts for the treatment of unilateral and bilateral LSCD. *also referred to as cornea tissue equivalent.

RAFT tissue equivalents were prepared in cell culture inserts (30 mm diameter, hydrophilic PTFE, $0.4 \mu \mathrm{m}$ pore size) (Merck Millipore) placed in 6 well plates using the confined flow compression method described by Levis et al. (2012). ${ }^{[14]}$ To make 3 tissue equivalents $9 \mathrm{ml}$ type I rat tail collagen (2.07 $\mathrm{mg} \mathrm{ml}^{-1}$, First Link UK) was mixed with $1.125 \mathrm{ml}$ Minimum Essential Medium (10x, Life Technologies), neutralised with 5M sodium hydroxide, and 660,000 fibroblasts (untreated) in fibroblast culture medium $(1.125 \mathrm{ml})$ added. This solution was split equally between 3 cell culture inserts to give 220,000 fibroblasts per tissue equivalent. Following 30 minutes at $37^{\circ} \mathrm{C}$ in a $5 \% \mathrm{CO}_{2}$ in air incubator to induce gelling, compression was performed for 15 minutes at room temperature. For compression the following were placed on top of the tissue equivalent; a circle of sterile nylon mesh, a circle of sterile filter paper, a roll of filter paper and a $35 \mathrm{~g}$ weight. Fibroblasts (MMC growth arrested) and epithelial cells (HLE or HOME) were co-cultured on the upper surface of 
these fibroblast populated tissue equivalents. Epithelial cells (126000, passage 1 unless otherwise specified) were seeded onto 189000 3T3s, 84000 HLF, or 84000 HOMF. These values were based on the following seeding densities: $1.8 \times 10^{4}$ epithelial cells $\mathrm{cm}^{-2}, 2.7 \times 10^{4} \mathrm{MMC}_{3 \mathrm{~T}} \mathrm{\textrm {cm } ^ { - 2 }}$, and $1.2 \times 10^{4} \mathrm{MMC} \mathrm{HLF} / \mathrm{HOMF} \mathrm{cm}^{-2}$. Cells were cultured on the tissue equivalents for 13 days in CECM (to produce a confluent epithelial layer) and then air-lifted for 5 days to induce stratification (multi-layering) of the epithelial cells.

\subsection{Removal of epithelial cells from tissue equivalents}

Epithelial cells were removed from the tissue equivalents with 10X trypsin:EDTA. The trypsin was quenched with CECM, cells centrifuged at 80-100g, washed with PBS and processed for either protein or RNA extraction.

\subsection{Polymerase chain reaction $(\mathrm{PCR})$}

RNA was isolated from epithelial cells using the RNeasy Plus Mini Kit (Qiagen) and quantified using an Eppendorf Biophotometer. For each sample, $0.3 \mu \mathrm{g}$ was used to synthesise cDNA using the Quantitect Reverse Transcription Kit (Qiagen). PCRs were performed as previously described ${ }^{\text {[20] }}$ on equal amounts of cDNA (with the following changes: 32 cycles for CK12, and 30 cycles for MUC16) using the primers previously described: ${ }^{[20]}$ Primer sequences were taken from published references, ${ }^{[21,50,51]}$ and checked using Primer-BLAST (National Centre for Biotechnology Information). In addition, sequencing of PCR products was also completed. Products were visualised by agarose gel electrophoresis using Hyperladder II (Bioline Reagents Ltd) as a molecular weight marker. Controls omitting reverse transcriptase and sample blanks were also performed. 


\subsection{Western blotting}

Protein was extracted from epithelial cells using RIPA buffer (Thermo Scientific) plus Halt Protease Inhibitor and EDTA (Thermo Scientific), and the concentration quantified using the Pierce BCA protein assay kit (Thermo Scientific). Western blotting was performed as previously described

${ }^{[20]}$ using 40 $\mathrm{g}$ of each sample and the following primary antibodies: PAX6 (Covance, PRB-278P), GAPDH (Millipore, MAB374), MUC16 (Abcam, AB134093) and p63 $\alpha$ (Cell Signaling Technology, 4892). Primary antibody dilutions used were: MUC16 (1:10,000); PAX6 (1:500); p63 $\alpha$ (1:800-1:100); and GAPDH (1:1500). The following secondary antibodies were used: goat antimouse HRP (P0447, Dako) (1:10,000) and goat anti-rabbit HRP (P0448, Dako) (1:5000-1:10,000). Membranes were visualised using ECL Select western blotting detection reagent (GE Healthcare) and a Fuji image reader (LAS-1000 Pro version 2.1). Densitometric analysis was performed using Image J software, and results were normalised to GAPDH.

\subsection{Electron Microscopy}

RAFT tissue equivalents (3 HLE donors, and 3 HOME donors) were fixed in Karnovsky's fixative and processed for transmission electron microscopy (TEM) and scanning electron microscopy (SEM). One human cornea was also processed as a positive control. Samples were visualised on the JEOL 1010 TEM (for TEM) or the Zeiss Sigma vpFESEM (for SEM).

\subsection{Transparency}

The absorbance of tissue equivalents or corneas at $475 \mathrm{~nm}$ (both on cell culture inserts) was measured using a Safire plate reader to give a measure of transparency. See Table S1 for details of experimental replicates and repeats. 


\subsection{Histology and fluorescent immunohistochemistry:}

Tissue equivalents were fixed in $4 \%$ paraformaldehyde (PFA) for 30 minutes at room temperature. A human cornea was also fixed for use as a positive control. The cornea/tissue equivalents were then embedded in paraffin for sectioning $(7 \mu \mathrm{m})$ with a microtome. A human buccal oral mucosal biopsy was also fixed and processed to see if PAX6 was expressed in this tissue. All sections were dewaxed in xylene followed by rehydration using 100\% IMS, 90\% IMS, 70\% IMS and de-ionised water.

For p63 $\alpha$ and PAX6, antigen retrieval was performed using sodium citrate buffer (pH6) at $95^{\circ} \mathrm{C}$ for 20 minutes followed by blocking with $10 \%$ goat serum at room temperature for 60 minutes. Sections were then incubated with either the primary antibody to $\mathrm{p} 63 \alpha$ (1:50, Cell signalling technology) or PAX6 (1:50, Covance) at room temperature for 60 minutes. Sections were then washed and incubated with the secondary antibody goat anti-mouse Alexa Fluor 594 (1:500; Invitrogen) for 60 minutes in the dark. After washing, samples were mounted with vectorshield DAPI (Vector Labs) and cover slipped. The samples were analysed using a Zeiss LSM 700 microscope. IgG controls were also performed for PAX6.

For MUC16 antigen retrieval was performed in sodium citrate buffer (pH6) at $95^{\circ} \mathrm{C}$ for 10 minutes and the slides were allowed to cool in the buffer at room temperature for 20 minutes. Following blocking in $10 \%$ goat serum for 60 minutes the primary MUC16 antibody (Abcam) was applied neat at room temperature for 10 minutes. The Dako REAL Detection system Peroxidase/ DAB+ kit (Dako) was used for the rest of the experiment. Dako REAL Link Biotinylated Secondary Antibody was applied neat at room temperature for 30 minutes and washed with PBS. Following this, Dako REAL $^{\text {TM }}$ Streptavidin Peroxidase was applied neat at room temperature for 30 minutes and washed with PBS. Dako REALTM DAB+ Chromogen was added to Dako REAL ${ }^{\text {TM }}$ HRP Substrate Buffer (1:50) and applied to the sections at room temperature for 10 minutes. Following PBS washes, the 
sections were counterstained with haematoxylin, mounted in DPX and cover slipped. Further analysis was performed using an inverted light microscope.

\subsection{Statistical analysis}

Statistical analysis was performed using GraphPad Prism software. One way ANOVA was performed (Bonferroni post-test) with $\mathrm{p}<0.05$ considered to be statistically significant. See table $\mathrm{S} 1$ for details of sample size for transparency data.

\section{Supporting information}

Supporting information is available from the Wiley Online Library or from the author.

\section{Acknowledgements}

JTD and MPL contributed equally to this work. The authors would like to thank Mr Alex Shortt (UCL and Moorfields Eye Hospital) for taking the oral mucosal biopsies. This research was funded by Fight for Sight, the Special Trustees of Moorfields Eye Hospital and the National Institute for Health Research (NIHR) Biomedical Research Centre at Moorfields Eye Hospital NHS Foundation Trust and UCL Institute of Ophthalmology. MPL's contribution to this activity was conducted under the auspices of the National Centre for Sport and Exercise Medicine (NCSEM) England, a collaboration between several universities, NHS trusts and sporting and public bodies. The views expressed are those of the authors and not necessarily those of NCSEM England or the partners involved.

\section{Conflict of Interest}

The authors declare no conflict of interest 


\section{References}

[1] A. J. Shortt, C. Bunce, H. J. Levis, P. Blows, C. J. Dore, A. Vernon, G. A. Secker, S. J. Tuft, J. T. Daniels. Stem Cells Transl Med. 2014,3,265.

[2] O. Baylis, F. Figueiredo, C. Henein, M. Lako, S. Ahmad. J Cell Biochem. 2011,112,993.

[3] S. Basu, M. M. Fernandez, S. Das, S. Gaddipati, G. K. Vemuganti, V. S. Sangwan. Br J Ophthalmol. $2012,96,1504$.

[4] A. J. Shortt, G. A. Secker, M. S. Rajan, G. Meligonis, J. K. Dart, S. J. Tuft, J. T. Daniels. Ophthalmology. $2008,115,1989$.

[5] T. Nakamura, C. Sotozono, A. J. Bentley, S. Mano, T. Inatomi, N. Koizumi, N. J. Fullwood, S. Kinoshita. Ophthalmology. 2010,117,2247.

[6] M. Pauklin, T. A. Fuchsluger, H. Westekemper, K. P. Steuhl, D. Meller. Dev Ophthalmol. 2010,45,57.

[7] S. M. Daya, A. Watson, J. R. Sharpe, O. Giledi, A. Rowe, R. Martin, S. E. James. Ophthalmology. $2005,112,470$

[8] Y. Satake, M. Dogru, T. Yamaguchi, D. Tomida, M. Hirayama, J. Shimazaki. JAMA Ophthalmol. $2013,131,920$.

[9] X. Qi, L. Xie, J. Cheng, H. Zhai, Q. Zhou. Ophthalmology. 2013,120,931.

[10] T. Nakamura, K. Takeda, T. Inatomi, C. Sotozono, S. Kinoshita. Br J Ophthalmol. 2011,95,942.

[11] Y. Satake, K. Higa, K. Tsubota, J. Shimazaki. Ophthalmology. 2011,118,1524.

[12] T. P. Utheim, O. A. Utheim, Q. E. Khan, A. Sehic. J Funct Biomater. 2016,7.

[13] H. J. Levis, A. K. Kureshi, I. Massie, L. Morgan, A. J. Vernon, J. T. Daniels. J Funct Biomater. 2015,6,50.

[14] H. J. Levis, G. S. Peh, K. P. Toh, R. Poh, A. J. Shortt, R. A. Drake, J. S. Mehta, J. T. Daniels. PLoS One. $2012,7, \mathrm{e} 50993$.

[15] H. J. Levis, R. A. Brown, J. T. Daniels. Biomaterials. 2010,31,7726.

[16] H. J. Levis, I. Massie, M. A. Dziasko, A. Kaasi, J. T. Daniels. Biomaterials. 2013,34,8860. 
[17] M. A. Dziasko, H. E. Armer, H. J. Levis, A. J. Shortt, S. Tuft, J. T. Daniels. PLoS One. 2014,9,e94283.

[18] M. Notara, A. J. Shortt, G. Galatowicz, V. Calder, J. T. Daniels. Stem Cell Res. 2010,5,188.

[19] A. J. Shortt, G. A. Secker, P. M. Munro, P. T. Khaw, S. J. Tuft, J. T. Daniels. Stem Cells. 2007,25,1402.

[20] A. R. O'Callaghan, L. Morgan, J. T. Daniels, M. P. Lewis. Regen Med. 2016.

[21] S. L. Madhira, G. Vemuganti, A. Bhaduri, S. Gaddipati, V. S. Sangwan, Y. Ghanekar. Mol Vis. $2008,14,189$.

[22] W. Li, Y. T. Chen, Y. Hayashida, G. Blanco, A. Kheirkah, H. He, S. Y. Chen, C. Y. Liu, S. C. G. Tseng. The Journal of Pathology. 2008,214,114.

[23] S. Kolli, S. Ahmad, H. S. Mudhar, A. Meeny, M. Lako, F. C. Figueiredo. Stem Cells. 2014,32,2135.

[24] H. J. Levis, J. T. Daniels. Curr Eye Res. 2016,41,1153.

[25] Y. Oie, R. Hayashi, R. Takagi, M. Yamato, H. Takayanagi, Y. Tano, K. Nishida. Br J Ophthalmol. $2010,94,1244$

[26] S. M. Sharma, T. Fuchsluger, S. Ahmad, K. R. Katikireddy, M. Armant, R. Dana, U. V. Jurkunas. Stem Cell Rev. 2012,8,696.

[27] H. Green. Bioessays. 2008,30,897.

[28] H. Miyashita, S. Shimmura, K. Higa, S. Yoshida, T. Kawakita, J. Shimazaki, K. Tsubota. Tissue Eng Part A. $2008,14,1275$.

[29] H. J. Levis, J. Menzel-Severing, R. A. Drake, J. T. Daniels. Curr Eye Res. 2013,38,41.

[30] I. Massie, A. K. Kureshi, S. Schrader, A. J. Shortt, J. T. Daniels. Acta Biomater. 2015,24,241.

[31] Y. Q. Zhang, W. J. Zhang, W. Liu, X. J. Hu, G. D. Zhou, L. Cui, Y. Cao. Tissue Eng Part A. 2008,14,295.

[32] R. Homma, H. Yoshikawa, M. Takeno, M. S. Kurokawa, C. Masuda, E. Takada, K. Tsubota, S. Ueno, N. Suzuki. Invest Ophthalmol Vis Sci. 2004,45,4320.

[33] S. Ahmad, R. Stewart, S. Yung, S. Kolli, L. Armstrong, M. Stojkovic, F. Figueiredo, M. Lako. Stem Cells. $2007,25,1145$.

[34] E. A. Blazejewska, U. Schlotzer-Schrehardt, M. Zenkel, B. Bachmann, E. Chankiewitz, C. Jacobi, F. E. Kruse. Stem Cells. 2009,27,642.

[35] T. S. Jiang, L. Cai, W. Y. Ji, Y. N. Hui, Y. S. Wang, D. Hu, J. Zhu. Mol Vis. 2010,16,1304. 
[36] E. A. Meyer-Blazejewska, M. K. Call, O. Yamanaka, H. Liu, U. Schlotzer-Schrehardt, F. E. Kruse, W. W. Kao. Stem Cells. 2011,29,57.

[37] S. Gu, C. Xing, J. Han, M. O. Tso, J. Hong. Mol Vis. 2009,15,99.

[38] J. Wu, Y. Du, M. M. Mann, J. L. Funderburgh, W. R. Wagner. Exp Eye Res. 2014,120,71.

[39] S. Gaddipati, R. Muralidhar, V. S. Sangwan, I. Mariappan, G. K. Vemuganti, D. Balasubramanian. Indian J Ophthalmol. 2014,62,644.

[40] P. Rama, S. Matuska, G. Paganoni, A. Spinelli, M. De Luca, G. Pellegrini. N Engl J Med. 2010,363,147.

[41] L. P. Ang, T. Nakamura, T. Inatomi, C. Sotozono, N. Koizumi, N. Yokoi, S. Kinoshita. Arch Ophthalmol. 2006,124,1543.

[42] C. G. Priya, P. Arpitha, S. Vaishali, N. V. Prajna, K. Usha, K. Sheetal, V. Muthukkaruppan. Eye (Lond). $2011,25,1641$.

[43] C. Sotozono, T. Inatomi, T. Nakamura, N. Koizumi, N. Yokoi, M. Ueta, K. Matsuyama, H. Kaneda, M. Fukushima, S. Kinoshita. Acta Ophthalmol. 2014,92,e447.

[44] M. Pathak, S. Cholidis, K. Haug, A. Shahdadfar, M. C. Moe, B. Nicolaissen, L. Drolsum. Acta Ophthalmol. $2013,91,769$.

[45] A. Shahdadfar, K. Haug, M. Pathak, L. Drolsum, O. K. Olstad, E. O. Johnsen, G. Petrovski, M. C. Moe, B. Nicolaissen. Exp Eye Res. 2012,97,1.

[46] T. Nakamura, T. Inatomi, C. Sotozono, L. P. Ang, N. Koizumi, N. Yokoi, S. Kinoshita. Ophthalmology. $2006,113,1765$.

[47] M. Kawashima, T. Kawakita, Y. Satake, K. Higa, J. Shimazaki. Arch Ophthalmol. 2007,125,1337.

[48] S. Bobba, S. Chow, S. Watson, N. Di Girolamo. Stem Cell Res Ther. 2015,6,23.

[49] N. Di Girolamo, M. Bosch, K. Zamora, M. T. Coroneo, D. Wakefield, S. L. Watson. Transplantation. $2009,87,1571$.

[50] E. Di lorio, V. Barbaro, A. Ruzza, D. Ponzin, G. Pellegrini, M. De Luca. Proc Natl Acad Sci U S A. $2005,102,9523$

[51] S. Krishnan, G. K. Iyer, S. Krishnakumar. Indian J Med Res. 2010,131,422. 
